Atıf Bilgisi: Sögüt, F. (2021). Dağlık Karabağ çatışması ve nefret söylemi: Youtube kullanıcı yorumları üzerine bir inceleme. INIF E-Dergi, 6(2), 306-324.

\title{
DAĞLIK KARABAĞ ÇATIŞMASI VE NEFRET SÖYLEMİ: YOUTUBE KULLANICI YORUMLARI ÜZERINE BİR İNCELEME
}

\author{
Dr. $\ddot{O} \breve{g r}$. Üyesi Fatih SÖ $\breve{G} \ddot{U} T^{*}$ \\ DOI: 10.47107/inifedergi.977259
}

\author{
Araștırma Makalesi** \\ Başvuru Tarihi: 01.08.2021 \\ Kabul Tarihi: 08.10.2021
}

Öz

Nefret söylemi, toplumsal yapı içerisinde "öteki” olarak konumlandırılan bir kişi ya da gruba karşı bu grubun ya da bireyin rkkına, cinsiyetine, cinsel yönelimine, engel durumuna bakılarak yöneltilen hakaret, aşağılama, küçümseme, alay etme gibi ifade biçimlerini kapsamaktadır. Bu ifade biçimlerinin yayılmasında medyanın kullanımı bu söylemlerin etkisini daha da güçlendirmektedir. Gelişen iletişim teknolojilerine paralel olarak ortaya çıkan yeni medya ortamları ise nefret söyleminin üretilmesi ve yaygınlaştırılmasına yeni bir boyut getirmiştir. Yeni medyanın sahip olduğu yapısal özellikleri nefret söyleminin bireysel olarak üretilmesinde, geniş kitlelere aktarılmasında, etki alanının genişletilmesinde önemli rol oynamaktadır. Bu çalışmada Dağlık Karabağ çatışmaları ekseninde yaygın olarak kullanılan video paylaşım ağı olan Youtube'daki nefret söylemi araştırılmıştır. Bu bağlamda bu çalışmanın temel amacı video paylaşım ağlarındaki nefret söylemini ortaya çıkarmaktır. Bu araştırmanın kuramsal temelini Erwin Gofmann'nın dramaturji teorisi oluşturmaktadır. Araştırma için Ermenistan'ın ArmNews televizyon kanalının Youtube kanalı ile Azerbaycan'nın İçtimaiTV kanalının Youtube kanalında yer alan ve 27 Eylül 2020- 09 Kasım 2020 tarihleri arasında yayınlanmış olan haber videolarına yapılan kullanıcı yorumları incelenmiştir. Yapılan kullanıcı yorumları içerik analizi ve eleştirel söylem çözümlemesi ile araştırılmıştır. Araştırma sonuçlarına göre hem Ermeni kullanıcılar hem de Azeri kullanıcılar haber videolarına yaptıkları yorumlarda yoğun bir biçimde nefret söylemine yer vermektedirler. Ermeni kullanıcılar daha çok etnik ve dinsel bir nefret söylemine başvururken Azeri kullanıcılar ise intikamcı ve sembolik bir nefret söylemini kullanmaktadır. Söylemi

Anahtar Kelimeler: Youtube, Kullanıcı Yorumlarl, Dramaturji Kuramı, Dă̆glk Karabağ, Nefret

\section{NAGORNO-KARABAKH CONFLICT AND HATE SPEECH: A REVIEW OF YOUTUBE USER COMMENTS}

\begin{abstract}
Hate speech includes forms of expression such as insult, humiliation, belittlement and ridicule against a person or group that is considered to be disadvantaged in society on grounds such as race, gender, sexual orientation and disability. The transmission of these forms of expression to large masses through the media increases the impact of hate speech. New media environments emerging in parallel with the developing communication technologies brought a new dimension to the production and dissemination of hate speech. The structural features of the new media play an important role in the individual production of hate speech, its transmission to large masses, and the expansion of its sphere of influence. In this study, hate speech on Youtube, which is a video sharing network widely used in the axis of Nagorno-Karabakh conflicts, was investigated. In this context, the main purpose of this study is to reveal hate speech in video sharing networks. The theoretical basis of this research is the theory of dramaturgy of Erwin Gofmann. For the research, user comments to the news videos on the Youtube channel of Armenia's ArmNews television channel and on the Youtube channel of Azerbaijan's İçtimaiTV channel and broadcast between September 27, 2020- November 9, 2020 were analyzed. User comments were investigated by content analysis and critical discourse analysis. According to the results of the research, both Armenian and Azerbaijani users use hate speech in their comments on the news videos. While Armenian users mostly resort to ethnic and religious hate speech, Azerbaijani users use vengeful and symbolic hate speech.
\end{abstract}

Keywords: Youtube, User Comments, Dramaturgy Theory, Nagorno-Karabakh, Hate Speech

\footnotetext{
* Kırklareli Üniversitesi, Sosyal Bilimler MYO, E-mail: fatih.sogut@klu.edu.tr, ORCID ID: 0000-0001-6529-9056

***Yazar / yazarlar, makalede araştırma ve yayın etiğine uyulduğuna ve kullanılan fikir ve sanat eserleri için telif hakları düzenlemelerine riayet edildiğine yönelik beyanda bulunmuştur.
} 


\section{Giriş}

İnsan hayatında önemli bir yere sahip olan iletişim çeşitli ihtiyaçlar sonucu ortaya çıkarken zaman içerisinde önemli değişimler göstermiştir. İnsanın kendisi gibi bireyleri ve çevreyi anlamlandırma ihtiyacıyla ortaya çıkan iletişim, insanların duygu, düşünce ve enformasyonu belirli yollarla ve araçlarla paylaşması olarak adlandırılabilir. Bireyler arası iletişimin önemli noktalarından biri kişiyi ya da toplumu etkilemek üzerinedir. $\mathrm{Bu}$ bağlamda insanlar iletişim amaçlı olarak birbirleriyle iletişim faaliyeti içinde bulunmakta ve birbirlerini etkilemeye çalışmaktadır.

Son y1llarda bilgi ve iletişim teknolojilerinde yaşanan önemli ilerlemeler, iletişim süreçlerini de yeniden şekillendirmiştir. Bu yeniden şekillendirmeyle insanlar artık çeşitli teknolojik araçları kullanarak zaman ve mekândan bağımsız olarak iletişime geçebilmektedir. Daha hızlanan ve kolaylaşan iletişim süreçleri ile insanlık geri dönülemez anlamda bir aşama kaydetmiştir. İletişim süreçlerinin bu kadar hızlı gelişimi olumlu olduğu kadar olumsuz etkileri de beraberinde getirmiştir.

Web 2.0 devrimiyle beraber insanlar sanal ortamda duygu, düşünce ve bilgiyi özgürce paylaşmaya başlamıştır. Günümüzde gelişen sosyal medya ortamları insanların çokça vakit geçirdikleri mecralar haline gelmiştir. Hayatımıza giren sosyal medya fenomeni ile paylaşım kültürünün gelişmesi bazı etik sorunları da gündeme getirmiştir. Sosyal medya uygulamaları; sosyal sorumluluk farkındalığı yaratmak, toplumu harekete geçirmek ve enformasyonun sınırsız paylaşımı gibi insanlık açısından faydalı işlevleri yerine getirirken diğer taraftan nefret söyleminin üretildiği ve yayıldığı alanlar haline de gelmiştir.

Bu çalışmada 2020 yılı içerisindeki Dağlık Karabağ çatışmaları ekseninde yaygın olarak kullanılan video paylaşım ağı olan Youtube'daki nefret söylemi araştırılmıştır. Bu bağlamda bu çalışmanın temel amacı video paylaşım ağlarındaki nefret söylemini ortaya çıkarmaktır. Bu araştırmanın kuramsal temelini Erwin Gofmann'nın dramaturji teorisi oluşturmaktadır. Araştırma için Ermenistan'ın ArmNews televizyon kanalının Youtube kanalı ile Azerbaycan'nın İçtimaiTV kanalının Youtube kanalında yer alan ve 27 Eylül 2020- 09 Kasım 2020 tarihleri arasında yayınlanmış olan haber videolarına yapılan kullanıcı yorumları incelenmiştir. Yapılan kullanıcı yorumları içerik analizi ve eleştirel söylem çözümlemesi ile değerlendirilmiştir.

\section{Kuramsal Bir Çerçeve Olarak Dramaturji Kuramı}

Sembolik etkileşimcilik görüşünün temel kavramsal kabulüne göre, kimlik ve kültür toplumsal etkileşim üzerine inşa edilmiştir (Oksman ve Turtiainen, 2004). Bu kuramsal çerçevenin üç temel saç ayağı vardır. İlk olarak insan davranışlarının anlamlandırılmasıdır. Bireyler davranışlarını çevresindeki kişilerin anlamlandırmasına bağlı olarak şekillendirmektedirler. İkinci olarak dil çok önemli bir araçtır. İnsanın toplumla etkileşimini sağlayan yegâne araç dildir. Son olarak ise düşence bu kuramsal çerçeve için önemlidir. Dil ile kurulan etkileşime verilen tepkiler üretilen anlamlar ve zihinsel süreçler düşünce ile ilgilidir.

Bireyin zihinsel durumu, işaretlere uyaranlara verilen tepkiler bütünsel bir düşünce yapısının parçalarıdır. Anlam, dil ve düşünce ile insan benliğinin çerçevesi çizilebilir. Benlik ve kimlik kavramları bu üç unsurun birbiri ile olan etkileşimi ile şekillenir. Toplum içerisinde yaşayan birey, bazı genelleştirmelere maruz kalır. Birey, toplumun ondan beklediği şekilde tutum ve davranışlar göstermek zorundadır.

Bu bağlamda, Goffman'ın (1959, s.202) teorik altyapısından bahsetmek gereklidir. Dramaturjik Yaklaşım; Chicago Okulu'nun sembolik etkileşimci geleneğinden etkilenen 
ve insan davranışlarını açıklamada tiyatro metaforunu kullanan, modern sembolik etkileşimciliğin en önemli isimlerinden Erving Goffman'ın geliştirdiği sosyolojik bir kavramdır. Goffman, ilk olarak 1959 yılında yayınlanan Günlük Yaşamda Benliğin Sunumu adlı çalışmasında, günlük yaşamdaki etkileşimler ve etkinlikler içinde sergilenen davranışlarla tiyatroda sergilenen rollerin benzerlik gösterdiğini ifade etmektedir. Aynı zamanda bu çalışmada değinilen Dramaturjik dünya görüşünün Shakespeare zamanına dayandığı ve Goffman'ın onun çalışmalarından etkilendiği görülmektedir. Goffman'a göre (2009), dünya bir tiyatro sahnesidir ve bütün insanlar istedikleri zaman sahneye çıkma ve sahneden ayrılma hakları olan birer oyuncudur. Bir birey sahnede pek çok role bürünebilmektedir ve tiyatro, insan yaşamındaki davranışları tanımlamada kullanılabilecek etkili bir metafordur. Dolayısıyla her bir toplumsal konum gerçek yaşamın bir oyun gibi, gerçek aktörler tarafından, gerçeğe uygun bir şekilde oynandığ tanımlanmaktadır. Dramaturjik Yaklaşım hem sahnedeki aktör hem de izleyiciler tarafından ele alınan iki yönlü bir etkileşime vurgu yapmaktadır. "Birey ve toplum arasında olduğu gibi, oyuncu ve izleyici arasında da güçlü bir bağ bulunmaktadır" (Kivisto ve Pitmann, 2012, s. 272). Bireyler sabit bir benlik algısı yaratmak için toplumsal izleyicilerine karşı çeşitli performanslar sergilemektedir. Goffman, bu performanslardan yola çıkarak toplumsal yaşantıyı, sahnede sergilenen bir tiyatro oyunu gibi görmeye odaklanmıştır. Dramaturji, bireyin kendini rol aracılığıyla sunmasını toplumla ilişkili olmanın bir yolu olarak görmektedir. Gerçek yaşamda sıradan statülerde bulunan bireyler, kendilerine yönelik bir izlenim oluşturmak için rollerini sergilemek ve bu izlenimi devam ettirecek şekilde hareket etmektedir (Gofmann, 1971, s.72). Dramaturjik Yaklaşıma göre insan eylemlerinin zamana, yere ve izleyiciye bağlı olduğu kabul edilmektedir. Goffman, kendinin kim olduğu duygusunun, sahnede doğrudan sergilenenden ortaya çıkan, dramatik bir etki olduğunu ifade etmektedir. Bir birey kendini diğerlerine kültürel değerler, normlar ve beklentiler temelinde sunmaktadır. Bu şekilde sunmaktaki amaç, titizlikle yürütülen performansın izleyiciler tarafından kabul edilmesinin sağlanmasıdır (Gofmann, 1963; Gofmann, 1967; Goffman, 2009). Goffman (1964, s.196) bireyin sabit/durağan ve bağımsız psikolojik bir varlık olmadığı, bunun yerine diğerleriyle etkileşimde bulunduğu ve bu etkileşimleri sürekli yeniden yapılandırdığından dolayı herhangi bir etkileşimin kesin bir anlamı olmadığını kabul etmektedir.

Goffman'ın metafor olarak kullandığı dramaturjik yaklaşım, insan deneyimlerinin anlamlı hale getirdiği kapsayıcı bir çatı içerisinde gelişmektedir. Bu çatılar, bireyin davranışlarını sınırlandırarak toplumsal hayatın belirli bir düzende yaşanmasına zorlamaktadır. Dolayısıyla oyunlar, alışkanlıklar ve aldatmacalar kendi kendilerini tekrar etmektedir (Gofmann, 1986).

Benlik sunumu, kişinin kendisi hakkında bazı bilgileri veya kendi imajını diğer insanlara aktarmaya çalıştığı davranıştır (Baumeister \& Hutton, 1987, s.71). Benlik sunumu, insan davranışındaki bir motivasyon sınıfını ifade eder. Bu motivasyonlar kısmen bireylerin istikrarlı eğilimleridir, ancak onları ortaya çıkarmak için durumsal faktörlere bağlidırlar. İki tür kendini sunum motivasyonu ayırt edilebilir (Baumeister, 1982). Biri (izleyiciyi memnun etmek), kişinin kendi sunumunu izleyicinin beklenti ve tercihleriyle eşleştirmesidir. Diğeri (kendini inşa etme), kişinin benlik sunumunu kendi ideal benliğiyle eşleştirmesidir. İzleyiciyi memnun etme güdüsü, özellikle farklı izleyicilerin farklı tercihleri olduğundan, durumlara göre değişir; kişi kendini, anne babasıyla birlikte komşularına misafirliğe giderken veya arkadaşlarıyla bir partiye katılırken olduğundan farklı sunar.

İzleyen bireyleri memnun etme anlayışı ilk olarak Jones ve Pittman (1982) tarafından tanımlanmıştır. Bu yazarlar, benlik sunumunun izleyiciye yönelik olabileceğine, 
ancak olumlu bir izlenim bırakmaya yönelik olmadığına dikkat çekti. İzleyiciyi memnun etmek yerine, biri kendini tehlikeli (gözdağı stratejisi), ahlaki açıdan erdemli (örneklendirme stratejisi) veya çaresiz ve muhtaç (dua stratejisi) olarak sunmak isteyebilir. $\mathrm{O}$ halde, tüm bu benlik sunumlarının ardındaki genel ilke, insanların kendilerini, izleyici üzerinde belirli ve faydalı bir izlenim yaratacak şekilde, izleyiciyi etkilemek veya manipüle etmek için kendilerini sunan kişinin yararına olacak şekilde sunmalarıdır. Çoğu zaman bu, izleyiciyi sevimli ve yetkin olarak etkileyerek gerçekleştirilir; ama bazen tehlikeli veya çaresiz görünmek en faydalısı olabilir (Baumeister \& Hutton, 1987, s.72).

İnternetin yaygınlaşması ile benliğin sunumu konusundaki geleneksel yaklaşımda da önemli değişiklikler olmuştur. "Çevrimiçi ortamlarda benlik sunumu ile ilgili önceki çalışmalar genellikle kişilerin kimliklerinin açıkça belli olmadığı, anonim (isimsiz) kullanıcılı ortamlardaki kimlik inşasına odaklanmıştır" (Uçar, 2015, s. 314). Bu çalş̧malarda bireylerin genellikle anonim online ortamlarda rol yapma oyunlarına dahil olduklarını ve anormal bazı davranışlar sergilediklerini göstermiştir. Flört siteleri üzerine yapılan çalışmalarda ise benliğin internette sunumu üzerine farklı sonuçlara ulaşılmıştır (Zhao, Grasmuck ve Martin, 2008, s.1836).

İnternet ortamlarında benliğin sunumuna yönelik ilk çalışmaların odağında chat odaları ve flört siteleri olmuştur. Bu çalışmalarda elde edilen sonuçlara göre bireylerin bu anonim ortamlarda başkaları gibi davranmaya meyilli oldukları ya da toplumca tasvip edilmeyen davranışlar içerisinde oldukları ortaya çıkmıştır (Ellison, Heino, ve Gibbs, 2006, s. 441).

Son yıllarda sosyal medya yoluyla benliğin sunumuna yönelik pek çok araştırma yapılmıştır. İşman, Buluş ve Yüzüncüyıl (2016), çalışmalarında dijital ortamda sosyalleşmeyi benliğin sunumu çerçevesinde açıklamışlardır. Koç (2017), araştırmasında engelli bireylerin sosyal medya yoluyla benliklerini nasıl sunduklarını araştırmıştır. Çakmak ve Baş (2017), üniversite öğrencilerinin İnstagram üzerinden benlik sunumlarını araştırmışlardır. Uçar (2015) ise başka bir sosyal medya mecrası olan Facebook üzerinden benliğin sunumunu ele almıştır. Eda Akgün (2018), Youtube üzerinden benliğin sunumunu araştırmıştır.

\section{Nefret Söylemi}

Avrupa Konseyi'nin Bakanlar Komitesi, nefret söylemini “1rkçı nefreti, yabancı düşmanlığını, anti-semitizmi veya hoşgörüsüzlüğe dayalı diğer nefret türlerini yayan, kışkırtan, teşvik eden veya meşrulaş̧ıran her türlü ifade biçimi” olarak tanımlar (Weber A. , 2009, s. 3). Bakanlar komitesinin tanımı homofobiyi içermese de homofobik söylemlerde nefret suçu kapsamında değerlendirilmektedir. Genel bir çerçevede nefret söylemi, rrkçılık, cinsiyetçilik ve homofobi gibi önyargı ve ayrımcılığa dayanan ifadeler olarak tanımlanabilir. Başka bir deyişle, nefret söylemi, söylemin ırk, din, etnik kimlik ve cinsel yönelime saldırmak için bir araç olarak kullanılmasıdır (Smolla, 1990). Buna göre Binark ve Çomu (2012), bu tür söylemin farklı bağlamlarını içeren altı tür nefret söylemi tanımlamaktadır: siyasi nefret söylemi, kadına yönelik nefret söylemi, yabancılara ve göçmenlere yönelik nefret söylemi, engellilere ve çeşitli hastalıklara karşı nefret söylemi, cinsel içerikli nefret söylemi, dini inanç ve mezhepten kaynaklanan nefret söylemi. Yine Binark ve Çomu, nefret söylemi terimini hoşgörüsüzlükten kaynaklanan ve önyargılarla beslenen nefreti popülerleştiren, destekleyen, savunan veya meşrulaş̧ıran her tür ifade olarak açılkarlar. 'Medyada Nefret Söyleminin İzlenmesi' projesini yürüten Hrant Dink Vakfına göre de nefret söyleminin temelinde önyargı, ırkçılık, yabancı düşmanlığı, tarafgirlik, ayrımcılık, cinsiyetçilik ve homofobi yatmaktadır. 
$\mathrm{Bu}$ anlamda nefret söylemi ırk, milliyet, etnisite ve din sınırlarını aşarak; cinsiyet, cinsel kimlik, cinsel yönelim, siyasi inançlar, engellilik ve çeşitli hastalıkları içerir hale gelmektedir. Genel olarak ayrımcılık ve hoşgörüsüzlüğe dayalı söylem, nefret söylemi olarak değerlendirilebilir. Terimin kapsamlı bir tanımı Cohen-Almagor (2011, s. 1-2) tarafından verilmiştir:

\begin{abstract}
Nefret söylemi, bazı gerçek veya algılanan doğuştan özelliklerinden dolayı bir kişiye veya bir grup insana yönelik önyargı saikli, düşmanca, kötü niyetli konuşma olarak tanımlanır. Cinsiyet, rrk, din, etnik köken, renk, ulusal köken, engellilik veya cinsel yönelimi içeren bu özelliklere karş1 ayrımcı, korkutucu, onaylamayan, düşmanca ve / veya önyargılı tutumları ifade eder.
\end{abstract}

Dahas1, Cohen-Almagor (2011), hedef grupların nefret söylemiyle yaralanmaya, insanlıktan çıkarmaya, taciz edilmeye, sindirilmeye, aşağılanmaya ve mağdur edilmeye niyetlendiğinin altını çiziyor; onlara karşı duyarsızlık ve gaddarlık teşvik ediliyor. Benzer şekilde Göregenli (2013), nefret söylemini toplumdaki gruplar arasında sistematik bir hiyerarşiyi temsil eden dışlanmışlık ve değersizleştirme ideolojisi olarak tanımlar. Aynı zamanda nefret söylemi ayrımcılığın en şiddetli yolu olan nefret suçunun zihinsel ve ideolojik arka planı olarak ortaya çıkar. Nefret söylemi, olumsuz önyargılı duygu ve tutumlardan beslenir; ancak herhangi bir nefret söylemini kişisel bir duygu, yani 'nefret' temelinde açıklamanın yetersiz olduğu düşünülmektedir. Bu tutum, nefret söyleminin hedef kitlesini suçlu ile eşitler ve nefret söylemini iletişimsizliğe indirger. Bununla birlikte, nefret söyleminin inşası, gücün kontrolüne bağlıdır ve sadece iktidar sahibi için mümkündür (Göregenli, 2013).

Dilin kullanımı ve dilin kullanımını içeren uygulamaların yaygınlaştığı ortam nefret söylemi için çok önemlidir (Binark ve Çomu, 2012). Buna göre, nefret söyleminin yaygınlaştııılmasında medyanın rolü tartışılmalıdır. Maigret (2011), nefret söylemi içeren medya içeriğinin bir toplumdaki fikirlerin çeşitliliğini bastırmaya hizmet ettiğini belirtmektedir. $\mathrm{Bu}$, belirli görüşlerin ve grupların "istenmeyen" hissetmesine ve kendi seslerini susturmasına neden olarak düşünülebilir. Böylelikle medyada kullanılan nefret söylemi, toplumu tek tipleştiren farklı yaşam tarzlarını, fikirleri ve görüşleri bastırmak için bir araç haline gelir. Bazı grupların görünmez ve bastırılmış hissetmesine neden olan bu nefret söyleminin sonucunun Noelle-Neumann'ın sessizlik sarmalı teorisine uygun olduğu söylenebilir.

Günümüzde nefret söyleminin en çok üretildiği ve dolaşıma sokulduğu mecralardan biri yeni medyadır (Öztekin, 2015). Özellikle sosyal medya ortamlarının katılımcı ve kontrolden uzak yapısı nefret söyleminin kolayca dolaşıma sokulmasını sağlamaktadır. Son yıllarda akademik alanda yeni medya ortamlarındaki nefret söylemini ele alan pek çok çalışma yapılmıştır (Alp, 2016; Özsoy ve Yıldız, 2013; Öztekin, 2015; Demirbaş, 2017; Karaman ve Işıkl1, 2016; Bulunmaz, 2015; Dondurucu ve Uluçay, 2015; Taş, 2017; Vardal, 2015; Kurt, 2019).

\title{
3. Video Paylaşım A ̆ğı Youtube
}

Günümüzde sosyal medya araçları içerisinde video paylaşımı denilince akla gelen ilk platform Youtube'dur. "Youtube, kullanıcıları için geniş bir işlev yelpazesine sahip, Web 2.0'ın katılımcı yapısını simgeleyen, gelişmeye devam eden çevrimiçi topluluktur" (Savage, 2015, s. 3). "Şubat 2005'te kurulan Youtube kullanıcılar tarafından oluşturulan videoları paylaşmak amaciyla tasarlanmıştır" (Ma, 2011, s. 3). "Youtube bir sosyal ă sitesidir ve günümüzde arama motoru olarak Google ne anlam ifade ediyorsa, videolu içerik aramak açısından da Youtube aynı anlamı ifade etmektedir" (Khan, 2017, s. 237). Youtube öncelikli olarak eğlence amaçlı bir platform olsa da yorum yapma gibi etkileşim odaklı yapısıyla sosyal medya iletişimini de desteklemektedir. Ayrıca Youtube videolarının 
eğitim amaçlı kullanımı da söz konusudur. Platform, video izleme ve video paylaşmanın yanın da sunduğu çeşitli işlevler ile hem aktif hem de pasif kullanıcı katılımını teşvik eder. $\mathrm{Bu}$ bağlamda, ana odağı video izlemek ve video paylaşmak olan Youtube, etkileşimi de destekleyen online bir yapıya kavuşmuştur.

Burgess ve Green (2009, s. 92)'e göre "Youtube'un amacı çevrimiçi video paylaşımının önündeki teknik engelleri kaldırmaktır". "Bu platformda minimum teknik bilgi birikimine sahip kullanıcılar, videolar yüklemekte, yayınlamakta ve görüntülemektedirler" (Smith, 2012, s. 10). Youtube platform olarak kullanıcilarının çektikleri videolarını yükleyerek, ünlü olmalarını sağlayan "Kendini Yayınlayı" (Broadcast Yourself) teşvik etmektedir. Platform canlı video görüntüleri ve ayrıntılı tanıtımlar sunar. $\mathrm{Bu}$ sebeple Youtube bireylerin satın aldıkları ürünleri göstermek, deneyimlerini paylaşmak, aynı zamanda yorum yaparak diğer kullanıcılar ile iletişim kurabilmek açısından faydalı bir ağ olarak ifade edilmektedir. "Böylelikle, bir ürünün avantajları veya dezavantajları, ürüne ilişkin memnuniyet ve memnuniyetsizlikler, tüm dünyada milyonlarca Youtube kullanıcısına iletilmektedir" (Wang, 2015, s. 1).

"Youtube içerik oluşturma kültürü ve sosyal ağ yeteneklerinin bir bileșeni olarak ortaya çıkmıştır" (Dearolph, 2014, s. 7). "Facebook ve Twitter ile karşılaştırıldığında, YouTube'un kendi tanıtım kültürü sayesinde güçlü bir etkisi vardır" (Fischer, Smith, \& Yongjian, 2012, s. 5). Youtube içerisindeki çok sayıda kanal sayesinde kullanıcılar kendi ilgi alanlarına göre bu kanallara abone olabilmektedir. Youtube'un önemli özelliklerinden birisi de içerik üreticilerle kullanıcılar arasında güçlü bağlar kurmasıdır. İçerik üreticileri ile kullanıcılar arasında kurulan bu bağ aynı zevkleri, duyguları ve inançları paylaşan bireylerin birbirlerini daha iyi tanımasını sağlar. Youtube topluluklarının ayrıca kendileriyle ilişkilendirilen birtakım kimlikleri de bulunmaktadır. Platformun içerik paylaşımı ve sosyal ağ özellikleri, "topluluğa yönelik aidiyet, bağlılık geliştirme ve kimlik oluşturmaya" olanak sunmaktadır. "Bu sebeple, Youtube internetteki en aktif ve en fazla topluluk katılımına sahip sosyal medya aracıdır" (Strangelove, 2010, s. 17).

\section{Dağlık Karabağ Sorunu}

Ermenilerin SSCB'de 1980'li y1llardaki glasnost ve perestroyka politikalarından faydalanarak Dağlık Karabağ bölgesinin Ermenistan SSC'ine bağlanmasını istemesi siyasi bir anlaşmazlığın doğmasına neden olmuştur (Mouridian, 1990). 1988 yılının başlarında Ermeniler tarafından Moskova da mitingler düzenlenmiş ve bu mitingler Rus yetkililer tarafından üstü kapalı şekilde desteklenmiştir (Aslanlı \& Hesenov, 2005). Moskova da yapılan bu gösterilerin daha çok katılımlı olanı ve daha büyük çaplısı Erivan'da devam etmiştir. (Cox \& Eibner, 1999). Yine 1988 yılı içerisinde Ermenistan Bilimler Akademisi, Mihail Gorbaçov'a binlerce Ermeni'nin imzasını taşıyan Karabağ ve Nahçıvan'ın Ermenistan'a bağlanmasını isteyen bir belgeyi teslim etti (Yerasimos, 2002). Dağlık Karabağ meclisi 20 Şubat 1988 tarihinde Ermenistan'a katılma yönünde bir karar almıştır (Libaridian, 1988). Azerbaycan'ın Dağlık Karabağ meclisinin aldığ 1 bu kararı tanımamasının ardından gösteriler ve şiddet olayları artmaya başladı. Dağlık Karabağ bölgesinde Azerilerin ve Ermenilerin yaşadığı yerlerde karşılıklı ölümlerle sonuçlanan olaylar meydana gelmiştir (Kaufmann, 2001). Ölümle sonuçlanan olaylar Azerbaycan topraklarına da sıçradı. Bakü ve Sumgayıt'ta Ermeni nüfusa yönelik saldırılar gerçekleştirildi. Dağlık Karabağ'ın başkenti Hankentin'de yaşayan Azerilere yönelik saldırılar artarak devam edince bölgedeki Azeri nüfusun tahliye edilmesine karar verildi. 1988 Kasım ayında Azerbaycan da Ermeni; Ermenistan da Azeri nüfus kalmamıştır. Azerbaycan yönetimi Sumgayıt'ta Ermenilere yönelik saldırıların Ermeni komplocular tarafından gerçekleştirildiğini ifade etmiştir (Abdullayev, 1999). 23 Mart 1988'de 
Sovyetler Birliği Yüksek Konseyi Dağlık Karabă̆'ın Ermenistan'a katılması talebini reddeder. Ancak bu karara karşılık Ermenistan yönetimi 15 Haziran 1988'de Karabağ'ın Ermenistan'a bağlandığını ilan eden bir karar alır.

1990'a gelindiğinde Azeri ve Ermeniler arasındaki gerilim silahlı çatışmalara dönüşmüştür. 13 Ocak'ta bir Ermeni'nin Bakü'de iki Azerbaycan Türk'üne saldırmasının ardından gerginlikler arttı. Azerbaycan da artan gerilimi kontrol altına almak isteyen Sovyetler Birliği Yüksek Konseyi 20 Ocak 1990 da Bakü’ye askeri birlikler gönderdi (Cafersoy, 2001). Sovyet Ordusunun Bakü'ye girmesinden sonra 3 Eylül 1991'de Dağlık Karabağ Cumhuriyeti İlan edildi. Aynı yılın 26 Kasım'ın da Azerbaycan yönetimi, Dağlık Karabağ'ın özerklik statüsüne son verdi ve bölgenin doğrudan merkezi yönetime bağlandığını açıkladı (Sapmaz, 2008). Dağlık Karabağ Cumhuriyet'inde yaşayan Ermeniler 8 Aralık 1991 de düzenlenen referandumla bağımsızlık kararı aldı.

1992 yılının başlarında sorun artık bir savaş haline gelmiştir. 2 yıllık silahlı çatışmanın ardından Ermeniler Dağlık Karabă̆ bölgesinin tamamını ele geçirmekle kalmayıp Azerbaycan'a ait 7 idari bölgeyi de işgal etmişlerdir. Dağlık Karabağ sorunu iki eski Sovyet cumhuriyetinin hem iç politikalarını hem de dış politikalarını şekillendirmektedir. BM ve AGİT gibi uluslararası kuruluşların barış amacıyla yaptığı girişimler sonuç vermemiştir. Soruna bir çözüm üretilememesi Ermeni tarafinın ele geçirdiği topraklar üzerindeki denetimini arttırmıştır. Azerbaycan tarafi ise mevcut statükonun Ermenistan'ın işine geldiğini ve bu durumunda çözümü zorlaştırdığını ifade etmektedir. Bağımsızlığını ilan eden Dağlık Karabă̆ Cumhuriyeti uluslararası alanda hiçbir devlet tarafından tanınmamıştır. Buna karşılık Dağlık Karabağ yönetimi kendi yönetimlerini meşrulaştırmak için 1996 sonbaharında başkanlık seçimi yapmıştır. Azerbaycan yönetimi ise bu seçimleri tanımamış, işgal altındaki topraklardan kaçan Azeri mültecilerin evlerine dönene kadar bölgedeki hiçbir seçimin geçerli olmayacağını belirtmiştir (Taşdemir, 2002). "Seçimlerin tanınması, etnik temizlik yoluyla bölgedeki nüfus yapısının ve dengesinin zorla değiştirilmesini üstü kapalı olarak kabul etmek olacaktır" (Cornell, 1997, s. 343).

1992-1994 arasındaki savaş Bişkek protokolü olarak adlandırılan ateşkes anlaşması ile sona ermiştir. $\mathrm{Bu}$ anlaşmadan sonra özellikle sınır bölgelerinde küçük çaplı silahlı çatışmalar meydana gelmiştir. İki ülke arasındaki son büyük silahlı çatışma 27 Eylül 2020 ile 9 Kasım 2020 tarihleri arasında meydana gelmiştir. 1,5 aylık dönemde her iki taraftan da asker ve sivil olmak üzere 5000'den fazla insan ölmüştür.

\section{Yöntem}

"Dağlık Karabağ Çatışması ve Nefret Söylemi: Youtube Kullanıcı Yorumları Üzerine Bir İnceleme" başlıklı çalışma kapsamında, en popüler video paylaşım ağı olan Youtube da Dağlık Karabağ bölgesinde 27 Eylül 2020 ile 10 Kasım 2020 tarihleri arasında yaşanan çatışmalarla ilgili haber videolarına yapılan kullanıcı yorumları analiz edilmiştir. Analiz için Azerbaycan ve Ermenistan kaynaklı İçtimaiTV (https://www.youtube.com/channel/UCCYhaH52lUEmfUjX-_OBAHg) ve ArmNews (https://www.youtube.com/user/ArmnewsTV) televizyon kuruluşlarının Youtube kanalındaki Dağlık Karabağ çatışmasına ait haber videolarına yapılan yorumlar seçilmiştir. İlgili kanallarda yer alan en yüksek izlenme sayısına sahip videolara yapılan yorumlar örnekleme dahil edilmiştir. Çalışma kapsamında aşağıdaki araştırma soruları belirlenmiştir.

- Youtube kullanıcı yorumlarında dağlık Karabağ savaşı ile ilgili nefret söylemi olarak değerlendirilebilecek söylem ve içerik mevcut mudur?

- Dağlık Karabağ savaşı ile ilgili Youtube da yer alan haber videolarına yapılan yorumlarda söylem ve içerik nasıl yapılandırılmıştır? 
- Dağlık Karabağ savaşı ile ilgili Youtube da yer alan haber videolarına Azeri ve Ermeni kullanıcıların yaptığ

$\mathrm{Bu}$ araştırma sorularına cevap bulmak amacıyla nitel araştırma yöntemi tercih edilmiştir. Araştırma tekniği olarak ise içerik çözümlemesi ve eleştirel söylem analizi uygulanmıştır. Robert Weber (1990, s. 125), içerik çözümlemesini "metinden geçerli çıkarımlar yapmak için kullanılan bir araştırma tekniği”" olarak tanımlamıştır. DowneWamboldt'a göre (1992, s. 314) ise içerik çözümlemesi; "belirli olayları açıklamak ve ölçmek için sözlü, görsel veya yazılı verilerden geçerli çıkarımlar yapmak için sistematik ve nesnel bir yol sağlayan bir araştırma yöntemidir". Bu çalışmada ayrıca Teun A. van Dijk tarafından kavramsallaştırılan eleştirel söylem çözümlemesi de kullanılmıştır.

\begin{tabular}{|c|c|c|c|c|}
\hline Video Adı & Tarih & Görüntülenme & $\begin{array}{c}\text { Yorum } \\
\text { Sayısı }\end{array}$ & Video Linki \\
\hline Akşam Haberleri & 26.10 .2020 & 221.694 & 692 & $\begin{array}{l}\text { https://www.youtube.com/watch?v=4n4q1 csgQ8 } \\
k \& t=11 \mathrm{~s}\end{array}$ \\
\hline $\begin{array}{l}\text { İslam'ı Türkiye- } \\
\text { Azerbaycan } \\
\text { faşizminden } \\
\text { ayırmak }\end{array}$ & 29.10 .2020 & 206.107 & 605 & $\begin{array}{c}\text { https://www.youtube.com/watch?v=_qXWFmhw } \\
\text { ITQ\& }=421 \mathrm{~s}\end{array}$ \\
\hline Akşam Haberleri & 27.10 .2020 & 183.232 & 505 & https://www.youtube.com/watch?v=fxIsVrS7jdo \\
\hline $\begin{array}{l}\text { Azerbaycan'ın } \\
\text { kiralamış olduğu } \\
\text { teröristler } \\
\text { uluslararası basında }\end{array}$ & 29.10 .2020 & 181.151 & 107 & $\begin{array}{c}\text { https://www.youtube.com/watch?v=kO_cik- } \\
\text { 4rwA }\end{array}$ \\
\hline $\begin{array}{c}\text { Terör, } \\
\begin{array}{c}\text { Azerbaycan'a zarar } \\
\text { veriyor }\end{array}\end{array}$ & 26.10 .2020 & 162.174 & 335 & $\begin{array}{c}\text { https://www.youtube.com/watch?v=gfBWL88sU } \\
40\end{array}$ \\
\hline
\end{tabular}

Tablo 2. İçtimaiTV Youtube Kanalından Seçilen Videolar ve Yorum Sayıları

\begin{tabular}{|c|c|c|c|c|}
\hline \multicolumn{1}{|c|}{ Video Adı } & Tarih & Görüntülenme & Yorum Sayısı & Video Linki \\
\hline $\begin{array}{c}\text { İtimai TV'nin } \\
\text { muhabiri işgalden } \\
\text { kurtarıan } \\
\text { bölgelerdeki } \\
\text { askerlerle konuştu }\end{array}$ & 03.10 .2020 & 1.372 .294 & 830 & https://www.youtube.com/watch?v=QBYV \\
_vvvl18\&t=8s
\end{tabular}

\section{Bulgular}

$\mathrm{Bu}$ bölümde iki farklı Youtube kanalında yayınlanan haber videolarına yapılan kullanıcı yorumları incelenmiştir. Ayrıca bir önceki bölümde belirtilen yollarla elde edilen verileri sunulmakta ve çözümlenmektedir. 


\section{1. İçerik Analizi Bulguları}

$\mathrm{Bu}$ çalışmada analizin taraflılığını azaltmak, kategorilerin ağırlığını tespit etmek için ilk önce veriler sayılara indirgenmiştir. Daha sonra sayısal verilerin yüzde oranları hesaplanmıştır. $\mathrm{Bu}$ amaçla seçilen Youtube videolarına yapılan yorumlar yazılı bir metin olarak kabul edilerek, bu yorumlar üzerinden bir kodlama işlemi yapılmıştır. İçerik analizi kategorileri oluşturulurken benzer araştırmalardan (Alp, 2016; Erjavec \& Kovačič, 2012) yararlanılmıştır.

Tablo 3. Arm News Youtube Kanalında Yayınlanan Videolara Yapılan Yorumlara Ait İçerik Analizi Bulguları

\begin{tabular}{|l|c|c|}
\hline \multicolumn{1}{|c|}{ Kategoriler } & Yorum Sayısı & Yüzde \\
\hline Küfür-Hakaret-Aşağılama & 449 & 20 \\
\hline Simgeleştirme & 292 & 13 \\
\hline Abartma-Yükleme-Çarpıtma & 202 & 9 \\
\hline Düşmanlık-Savaş Söylemi & 808 & 36 \\
\hline Moral Söylemi-Dua & 471 & 21 \\
\hline Tespit Edilemeyen & 22 & 1 \\
\hline Toplam & 2.244 & $\% 100$ \\
\hline
\end{tabular}

Arm News Youtube kanalındaki içerik analizi bulgularına baktığımızda sırasıyla 808 (\%36) yorumla düşmanlık-savaş söylemi, 471 (\%21) yorumla moral söylemi-dua, küfür-hakaret-aşağılama 449 (\%20), simgeleştirme 292 (\%13), abartma-yükleme-çarpıtma 202 (\%9) ve son olarak da tespit edilemeyen $22(\% 1)$ yorum bulunmuştur.

Tablo 4. İctimai TV Youtube Kanalında Yayınlanan Videolara Yapılan Yorumlara Ait İçerik Analizi Bulguları

\begin{tabular}{|l|c|c|}
\hline \multicolumn{1}{|c|}{ Kategoriler } & Yorum Sayısı & Yüzde \\
\hline Küfür-Hakaret-Aşağılama & 373 & 24 \\
\hline Simgeleştirme & 171 & 11 \\
\hline Abartma-Yükleme-Çarpıtma & 186 & 12 \\
\hline Düşmanlık-Savaş Söylemi & 652 & 10 \\
\hline Moral Söylemi-Dua & 155 & 1 \\
\hline Tespit Edilemeyen & 15 & $\% 100$ \\
\hline Toplam & 1554 & 42 \\
\hline
\end{tabular}

İçtimaiTV Youtube kanalına ait haber videolarına yapılan yorumların içerik analizi bulgularına baktığımızda ise sırasıyla düşmanlık-savaş söylemi $652(\% 42)$, küfür-hakaretaşağılama 373 (\%24), abartma-yükleme-çarpıtma 186 (\%12), moral söylemi-dua 155 (\%10), tespit edilemeyen ise 15 (\%1) dir.

\subsection{Söylem Analizi Bulguları}

Söylem analizi uygulanacak yorumların seçiminde yargısal örnekleme yöntemi uygulanmıştır. " $\mathrm{Bu}$ yöntemde örneklem araştırmacının amacına uygun bir şekilde kümelere ayrılmakta ve bu kümelerden araştırmaya en uygun olduğu düşünülen metinler analiz için seçilmektedir" (Şahin, 2011, s. 125). Bu aşamada seçilen videolara yapılan yorumlar söylem bakımından üç ayrı gruba ayrılmış ve gruplarda en yüksek beğeni sayısına sahip 
dört yorum analize dahil edilmiştir. T. Van Dijk'in eleştirel söylem analizi yöntemine uygun olarak yorumların cümle ve sözcük yapıları incelenerek söylemin nasıl bir ideolojik ve anlamsal yapıyla oluşturulduğu araştırılmıştır. Girdilerdeki söylemin diğer söylemlerle ilişkisi ve bağlamsal yapısı da ortaya konulmuştur.

\subsubsection{ArmNews Youtube kanalına ait söylem analizi bulguları}

\section{Düş̧manlık Içeren Söylemler}

“Korkunç suçlar işlemek için Türkiye'den özel bir müfreze gönderildi” Raffi Hovhannisyan

“Düşmanların ölümlerini duymak çok güzel ve çok teşekkür ederim” Sona Yesayan

“Erdoğan, Ermenistan’a saldıracak dünya tepkisiz!!!” Liliya Hovhannisyan

“Azerbaycan, Aliyev ile utanç verici bir terör ülkesi oldu” Arik Chobanyan

ArmNews kanalında haber videolarına yapılan yorumlarda makro düzlemde tematik olarak düşmanlık içeren söylemlerin yoğunluğu dikkat çekicidir. Örnek olarak seçilen yukarıdaki yorumlarda da görüldüğü gibi savaş psikolojisi içerisinde karşı tarafi şeytanlaştırma, doğruluğu tam olarak teyit edilmemiş haberler etrafinda düşmanlık söylemini haklılaştırma gayreti görülmektedir. Söylemlerde dikkat çeken bir diğer noktada dünyanın Karabă̆ çatışmalarına karşı sessiz kaldığı serzenişidir. Mikro düzlemde ise nedensellik ilişkisi olarak Türkiye'nin Azerbaycan'a verdiği destek öne çıkarılmaktadır.

\section{Moral Destek ve Dua Içeren Söylemler}

“Tanrı askerlerimizi korusun, onları zafere taşısın” Ruzanna Oganesyan

"Tanrı askerlerimizi korusun. Tanrı seni korusun sevgili Abraham. Ermeni kahramanlarına cesaret, zafer ve onur" A D

"Çok iyi, Ali ve Azeriler çok utanç verici bir cezayla karşı karşıya. Dedikleri gibi, çukur açan kişi deliğe kendisi düşüyor, şimdi Müslümanları öldürün” Lyudmila Hakhumyan

"Bütün Hristiyanlar için savaşan askerlerimizi koru Tanrım” Levon Jan

Ermeni kullanıcıların yaptığı yorumlarda düşmanlık söyleminden sonra en s1k rastlanan söylem biçimi moral ve dua söylemleridir. Makro düzlemde tematik olarak Hristiyanlığa referansla savaşan Ermeni askerlere yönelik dua söylemleri dikkat çekmektedir. Savaş psikolojisi içerisinde dini duyguların bir sığınma ya da moral kaynağı olduğu söylenebilir. Bu söylemlerde ayrıca savaşılan tarafın Müslüman barbarlar olduğu düşüncesi vurgulanmaktadır. Bu bağlamda Ermeni kullanıcıların dini kökenli bir nefret söylemini sıklıkla kullandıkları söylenebilir. Mikro düzlemde kelime seçimlerine baktığımızda Hristiyan ve Müslüman ayrımına vurgu yapan kelimeler kullanılmıştır. Bilge (2016, s. 4), dini ve mezhep temelli nefret söylemi ile diğer nefret söylemlerinde olduğu gibi, bireylerin ya da toplumsal grupların kendilerinden farklı şekilde inananları ötekileştirerek kendi kimliklerini yeniden kurmayı amaçladıklarını belirtir. Ermeni kullanıcılar Hristiyan kimliklerini öne çıkararak düşmanlarını dini olarak ötekileştirmektedir.

\section{Simgeleştirme, Abartma ve Irkçılık İçeren Söylemler}

“Türkler sonsuza kadar kahrolsun” Varduhi Tsaturyan 
"Küçük Ermenistan sadece Azerbaycan ile değil, NATO ülkesi Türkiye ile değil, dünya terörizmiyle de savaşıyor. Ermenistan modern Sparta oldu ve bu dünya kahramanlık tarihine geçecek" Artur777lion

“Karabağ size kalmayacak mongollar” Astghik Pyunik

"Tanrım bizi Türk barbarların zulmünden koru” Genopiya Ghahramanyan

Avrupa Konseyi'nin Bakanlar Komitesi'nin nefret söylemi üzerine Tavsiye Kararı'nda ırkçılık içeren nefret söylemi saldırgan milliyetçilik ve etnik merkezcilik şeklinde ifadesini bulan hoşgörüsüzlüğe dayalı nefret söylemi türü olarak tanımlanmaktadır (Weber A. , 2009). Simgeleştirme ise İnceoğlu ve Sözeri tarafından (2012, s. 24) "doğal kimlik öğesini nefret, aşağılama unsuru olarak kullanma olarak tanımlanmıştır". Bu tanımlar doğrultusunda yorumların tematik yapısında irkçı ifadeler göze çarpmaktadır. Makro yapıda söylemler incelendiğinde tematik olarak Türk etnik kimliğinin hedefe koyulduğu görülmektedir. Mikro yapıda dikkat çeken nokta ise kelime seçimleridir. "Barbar" ve "mongol" gibi aşağılayıcı sözcük seçimleri kullanılmıştır.

\subsection{2. İctimai TV Youtube kanalına ait söylem analizi bulguları}

\section{Düşmanlık İçeren Söylemler}

"Karabăg Azerbaycan'dır. Defolun Azerbaycan toprağından Ermeni alçakları" Dinim İslam Kitabim Quran

“Allah korusun sizleri aslanlar Mubariz İbrahimovun intikamini alin” Deniz Deniz

“Ölün geberin bizim yaşadıklarımızın yanında sizin yaşadıklarınız hiçtir” Turane Huseyinova

"Sıçanlar gemiyi terk ediyor. Böyle kaçarsınız işte. Sizin gibiler barıştan ateşkesten anlamaz" Nuriyya Taqiyeva

Azeri kullanıcıların haber videolarına yaptığı yorumlarda \%42'lik bir oranla düşmanlık içeren yorumlar önemli bir ağırlığa sahiptir. Makro düzeyde tematik olarak bakıldığında ise yorumlarda intikamcı bir bakış söz konusudur. "İntikam, genel olarak kendisine yapılan olumsuz veya haksız davranışa karşı, öfke ile verilmek istenen tepkisel davranış olarak tanımlanabilir. İntikam, toplumsal amaçlara hizmet eden sosyal ve ahlaki saygınlığını geri kazanmak adına yapılmak istenen bir zarar verme fiilidir" (Şener, 2013, s. 4). Burada Azeri kullanıcıların 1992-1994 yılları arasındaki Karabağ çatışmalarında yaşadıkları kötü olayların etkisiyle yorumlarda bulundukları söylenebilir. Azeri kullanıcıların yorumlarındaki "intikam" ortak paydası akıllara toplumsal hafiza kavramını getirmektedir. Her bireyin bir geçmişi olduğu gibi bireylerden oluşan toplumlarında bir geçmişi bulunmaktadır. Toplumun yaşadığı şeyler toplumla birlikte tarihsel süreç içerisine taşınır. "Geçmişle ilişki kurulurken, burada bahsedilen geçmişle ilişki geçmişin nasıl hatırlandığı, hangi yönleriyle hatırlandığ şekillenir" (Sancar, 2007, s. 28). Geçmişle kurulan ilişkiye göre ya bir hatırlama kültürü ya da bir unutma kültürü geliştirilmiş olur. Geçmişteki savaşın kötü anıları Azerbaycan'ın toplumsal hafızasında önemli bir yere sahip olduğu bu yorumlardan anlaşılmaktadır. Mikro düzeyde kelime seçimlerinde de intikam duygusunu destekleyen kelime seçimleri bulunmaktadır.

\section{Moral Destek ve Dua İçeren Söylemler \\ “Azerbaycan askeri...Allah'1ma emanet olun” Arif Talibov \\ "Ya Allah bismillah Allahu Ekber" vuqar xelilov}


“Çok şükür Yarabbim sen desteğini esirgeme” Asker Aliyev

"Maşallah helal olsun size Allah sizi korusun. İnşallah hepinizi Şuşa da göreceğiz" Adil Veliev

Azeri kullanıcıların moral destek ve dua içeren söylemlerinde İslami referanslar öne çıkmaktadır. İslam dini için dua önemli bir kavramdır. Söylev'e göre (2018, s. 140), İslamiyet'te dua "Yaratıcının azameti karşısında kulun zaaflarını ve acizliğini kabul ederek sevgi ve tazim duyguları içinde Allah'a yönelmesi olayıdır". Kuran-1 Kerimde de sıklıkla hastalık ve savaş gibi durumlarda dua etmenin önemi vurgulanır. Müftüoğlu'na göre (2020, s. 8) de dua, "insanların üzüntülü, sıkıntılı, korkulu hallerinde, yalnızlık ve ümitsizlik duygularına kapıldıklarında, ani değişmelerle gelen kriz durumlarında, maruz kaldıkları yeni duruma uyum sağlama ve baş edebilme becerilerini geliştirmelerine yardımcı olmayı, varsa sorularını cevaplamayı, hayatlarına yeni bir anlam vermelerine eşlik ederek onlara moral kazandırmayı ifade etmektedir". Bu bağlamda Azeri kullanıcılar için dua'nın motivasyonel yönü daha önemlidir. Mikro düzeyde kelime seçimlerine baktığımızda "inşallah", "maşallah" gibi dini anlamları olan kelime seçimleri öne çıkmaktadır.

\section{Simgeleştirme, Abartma ve Irkçılı İçeren Söylemler}

"En büyük keyif askerimizin Ermeni bayrağını tekmelemesini seyretmek" Azada Ahmadova

“Bu videodan sonra Ermeniler gitsinler kendilerini assınlar” Rashid Novruzov

“Allahina kurban kardaş yakın o Ermenistan bayrağını” Adlan Yilmaz

“Ermeniler bakıp çatlasın” İlham İlyasov

Azeri kullanıcılar, Ermenilere karşı 1rksal bir nefretten ziyade simgesel bir nefret duymaktadır. Bu simgesel nefret Ermenistan bayrağı üzerine toplanmıştır. Makro düzeyde tematik olarak simgesel bir nefret söylemi görülmektedir. Bayrağın sembolik anlamı üzerinden bir nefret söylemi üretilmektedir. Yukarıdaki yorumlarda dikkat çeken bir diğer nokta ise nispet duygusudur. $\mathrm{Bu}$ noktada nispetizm kavramına değinmek gerekiyor. "Nispetizm, sosyal medyada bireylerin farklı bir kişiliğe bürünerek, çok mutlu ve kusursuzmuş gibi çevresine nispet yaptığ 1 diğer bir deyişle -mış gibi yaparak/davranarak aslında kendi içinde yalnız ve mutsuz insanların kendilerini gizlemek amacıyla gösteriş yaptıkları kavram olarak kendisine yer bulmuştur" (Y1ld1z, 2017, s. 94). Y1ldız'ın da belirttiği gibi sosyal medya platformları bireylerin psikolojik olarak kendilerini tatmin ettikleri nispet alanları olmuştur. Azeri kullanıcılar için Karabağ çatışmalarında kazanılan başarılar Ermenilere karşı bir nispet olgusu olarak görülmüştür.

\section{Sonuç ve Öneriler}

Önyargıya dayalı ve hoşgörüsüzlük temelli nefret biçimlerini yayma davranışı olarak adlandırabileceğimiz nefret söylemi; gündelik yaşam içinde karşımıza çıkabilen ayrımcılığın söylem yoluyla yeni bir biçim kazanmasıdır. Ayrımcılık ve nefret söylemi sadece etnik, dini ve ırkçı bir bakışın içinde yer almamakta toplumun pek çok kesimi içinde kendine yer bulabilmektedir. Toplumun günlük yaşam pratiklerinin içine sinmiş olan ve nefret söylemi olarak değerlendirilebilecek pek çok dilsel kod bulunmaktadır. Bu bağlamda nefret söylemi hakaret, aşağılama ve küfür gibi kullanımların ötesinde etnik, dini ve cinsiyetçi temelli algının derinlemesine analizini gerektirmektedir.

Nefret söyleminin önemli yayıcılarından biri de medyadır. Özellikle son yıllarda hızla gelişmekte olan yeni medya teknolojileri ve sosyal medya nefret söyleminin 
yayılmasını kolaylaştırmaktadır. Sosyal medya mecralarında üretilen nefret içerikli mesajlar pratik olarak dünyanın her yerine internet ile ulaşabilmektedir.

$\mathrm{Bu}$ çalışmada Youtube üzerinden üretilen nefret söylemi üzerinde durulmuştur. Dağlık Karabağ çatı̧̧ması özelinde haber videolarına yapılan kullanıcı yorumları incelenmiştir. $\mathrm{Bu}$ çalışma ile cevabı aranan ilk araştırma sorusu; Youtube kullanıcı yorumlarında dağlık Karabağ savaşı ile ilgili nefret söylemi olarak değerlendirilebilecek söylem ve içerik mevcut olup olmadığıdır? Bu bağlamda savaşın iki tarafindan da yapılan yorumlarda hem içerik hem söylem olarak yoğun bir nefret söylemi söz konusudur. Yıllardır çözülemeyen bölgesel bir sorunun ve beraberindeki kanlı savaşın ortaya çıkardığı karşılıklı bir nefret kullanıcı yorumlarında gözlemlenmiştir.

İkinci araştırma sorusu ise Dağllk Karabağ savaşı ile ilgili Youtube da yer alan haber videolarına yapılan yorumlarda söylem ve içeriğin nasıl yapılandırıldığıdır? Her iki kullanıcı grubunun yorumları incelendiğinde içerik ve söylem olarak benzer bir tematik yapılandırma bulunmaktadır. Yazılan yorumlar içerik ve söylem olarak ırksal, dini ve ötekileştirici bir nefret olgusu ile yapılandırılmıştır.

$\mathrm{Bu}$ çalı̧̧ma ile cevabı aranan son araştırma sorusu ise Dağlık Karabağ savaşı ile ilgili Youtube da yer alan haber videolarına Azeri ve Ermeni kullanıcıların yaptı̆̆ı yorumlarda ne gibi farklılıklar vardır sorusudur. Azeri ve Ermeni kullanıcıların yoğun bir biçimde nefret söylemi olarak değerlendirilebilecek yorumları olmakla beraber aralarında nefretin kökeni ve yansıtma biçimi bağlamında önemli farklılıklar bulunmaktadır. Bu farkları madde madde siralayacak olursak;

- Ermeni kullanıcılarda Azeri kullanıcılara nazaran yorumlarda ırkçı nefret daha fazla öne çıkmaktadır. Irkçı ve etnik nefret "Azeri" etnik kimliğinden daha da öte "Türk" etnik kimliğine yöneliktir.

- Ermeni kullanıcılar yorumlarında dini farklılıkları nefret söyleminin bir odağı haline getirmişlerdir. Ermeni kullanıcılar için bu savaş Hristiyanlarla Müslümanlar arasındaki bir savaştır. Ermeni kullanıcılar bu şekilde nefret söylemini haklılaşıırmaya çalışmıştır.

- Azeri kullanıcıların yorumlarında rövanşist ve intikamcı bir bakış ağır basmaktadır. Güncel savaşta alınan başarılar geçmişteki kayıpların bir intikamı olarak değerlendirilmektedir.

- Azeri kullanıcıların bazı yorumlarında nispet olgusu hakaret ile birleşerek bir nefret söylemine dönüşmüştür. Ermeni bayrağına yönelik sembolik bir nefrette söz konusudur.

Sonuç olarak birbirinden farklı nedenlerle ve biçimlerle de olsa Azeri ve Ermeni Youtube kullanıcıları karşlıklı nefret içeren söylemlerini internet ortamında yaymaktadırlar. Savaşın psikolojisi karşılıklı nefret söylemini haklı kılmamaktadır. Bu tarz nefret söylemleri daha yoğun bir öfkenin ortaya çıkmasına ve buna bağlı olarak da daha fazla şiddettin yaşanmasına neden olur.

Elde edilen bulguları Erwin Goffman'ın teorileştirdiği dramaturji kuramı ve benliğin sunumu bakışından değerlendirecek olursak Azeri ve Ermeni kullanıcılar Youtube ortamında kendi benliklerinden uzaklaşarak kendilerini var olan savaşın bir savaşçısı gibi konumlandırmaktadır. Goffman, teorisinde günlük hayatın birey için bir tiyatro sahnesi olduğunu belirtir. Bu bağlamda Youtube gibi anonim internet mecraları bireylerin gerçek kimliklerini sundukları bir alandır. Youtube da yorum yapan Azeri ve Ermeni kullanıcilar Youtube'u savaş alanın bir parçası kendilerini de bu alanın savaşçıları gibi görmektedirler. 
Nefret söyleminin yeni medya ortamlarında yayılmasını engellemek üzerinde düşünülmesi gereken bir noktadır. Özellikle sosyal medya mecralarının etkili kontrol ve filtreleme mekanizmaları oluşturarak nefret içeren yorumların ve paylaşımların önüne geçmesi gerekmektedir. Bununla beraber yeni medya ortamlarını gözlemleyen ve bu ortamlardaki nefret suçlarını raporlayan sivil toplum kuruluşlarının da devlet tarafından desteklenmesi nefret söyleminin internet üzerinden yayılarak toplumsal düşmanlıkların ve huzursuzlukların doğmasına engel olacaktır.

\section{Extended Abstract}

Hate speech includes forms of expression such as insult, humiliation, belittlement and ridicule against a person or group that is considered to be disadvantaged in society on grounds such as race, gender, sexual orientation and disability. The transmission of these forms of expression to large masses through the media increases the impact of hate speech. New media environments emerging in parallel with the developing communication technologies brought a new dimension to the production and dissemination of hate speech. The structural features of the new media play an important role in the individual production of hate speech, its transmission to large masses, and the expansion of its sphere of influence.

In this study, hate speech on Youtube, which is a video sharing network widely used in the axis of Nagorno-Karabakh conflicts, was investigated. In this context, the main purpose of this study is to reveal hate speech in video sharing networks. The theoretical basis of this research is the theory of dramaturgy of Erwin Gofmann. In this context, it is necessary to talk about Goffman's theoretical background. Dramaturgical Approach: It is a sociological concept developed by Erving Goffman, one of the most important names of modern symbolic interactionism, influenced by the symbolic interactionist tradition of the Chicago School and using the theater metaphor to explain human behavior. Goffman, in his work The Presentation of Self in Daily Life, first published in 1959, states that the behaviors displayed in daily life interactions and activities are similar to the roles displayed in the theater. At the same time, it is seen that the dramaturgical world view mentioned in this study is based on Shakespeare's time and Goffman was influenced by his works. According to Goffman, the world is a theater stage, and all people are actors who have the right to come and leave whenever they want. An individual can take on many roles on the stage, and theater is an effective metaphor that can be used to describe behavior in human life. Therefore, each social position is defined as a scene where real life is played by real actors, like a play, in a realistic way. The Dramaturgical Approach emphasizes a two-way interaction addressed by both the actor on stage and the audience.

For the research, user comments to the news videos on the Youtube channel of Armenia's ArmNews television channel and on the Youtube channel of Azerbaijan's İçtimaiTV channel and broadcast between September 27, 2020 - November 9, 2020 were analyzed. User comments were investigated by content analysis and critical discourse analysis.

The first research question whose answer is sought with this study; Is there any discourse and content in Youtube user comments that can be considered as hate speech about the Nagorno-Karabakh war? In this context, in the comments made by both sides of the war, there is an intense hate speech in terms of both content and discourse. For years, a mutual hate created by an unsolved regional problem and the accompanying bloody war has been observed in user comments.

The second research question is, how are the discourse and content structured in the comments made to the news videos about the Nagorno-Karabakh war on Youtube? When 
the comments of both user groups are examined, there is a similar thematic structure in terms of content and discourse. The comments written are structured in terms of content and discourse with a racial, religious, and marginalizing hate phenomenon.

The last research question whose answer is sought with this study is the question of what kind of differences are there in the comments made by Azerbaijani and Armenian users to the news videos about the Nagorno-Karabakh war on Youtube. Although Azerbaijani and Armenian users have comments that can be considered as hate speech, there are important differences between them in terms of the origin of hate and its reflection. If we list these differences item by item;

- Racist hatred is more prominent in comments among Armenian users compared to Azerbaijani users. Racist and ethnic hatred is more directed against the "Turkish" ethnic identity than the "Azeri" ethnic identity.

- Armenian users have made religious differences a focus of hate speech in their comments. For Armenian users, this war is a war between Christians and Muslims. In this way, Armenian users tried to justify hate speech.

- A revanchist and vengeful view prevails in the comments of Azerbaijani users. The achievements of the current war are considered as revenge for past losses.

- In some comments of Azeri users, the phenomenon of relativity combined with insult has turned into a hate speech. There is a symbolic hate for the Armenian flag.

As a result, Azeri and Armenian Youtube users spread their mutual hate speech on the internet, albeit for different reasons and forms. The psychology of war does not justify mutual hate speech. This kind of hate speech causes more intense anger and consequently more violence.

If we evaluate the results from the perspective of the dramaturgy theory theorized by Erwin Goffman and the presentation of the self, Azerbaijani and Armenian users move away from their self in the Youtube environment and position themselves as a warrior of the existing war. Goffman states in his theory that daily life is a theater stage for the individual. In this context, anonymous internet channels such as Youtube are a field where individuals present their true identities. Azeri and Armenian users who comment on YouTube are part of the battlefield and see themselves as fighters of this field.

\section{Kaynakça}

Abdullayev, A. (1999). Ermənistanin Azərbaycana Qarşi Hərbi Təcavüzü və Heydər Dliyevin Sülh Strategiyasi. Bakü: Elm.

Akgün, E. (2018). Sosyal medya platformlarından Youtube üzerinden benlik sunumunun dramaturjik bir analizi. Yeni Medya (4), 29-49.

Alp, H. (2016). Çingenelere yönelik nefret söyleminin Ekşi Sözlük’te yeniden üretilmesi. Ankara Üniversitesi ILEF Dergisi, 3(2), 143-172.

Aslanlı, A. ve Hesenov, I. (2005). Haydar Aliyev Dönemi Azerbaycan dış politikası. Ankara: Platin Yayınları.

Baumeister, R. F. (1982). A self-presentational view of social phenomena. Psychological Bulletin, 91, 3-26.

Baumeister R.F. and Hutton D.G. (1987). Self-presentation theory: Self-construction and audience pleasing. In: Mullen B., Goethals G.R. (Eds.) Theories of group behavior. Springer Series in Social Psychology. Springer, New York, NY. 
Bilge, R. (2016). Sosyal medyada nefret söyleminin inşası ve nefret suçlarına ilişkin yasal düzenlemeler. Yeni Medya Elektronik Dergisi, Güz(1), 1-14.

Binark, M., ve Çomu, T. (2012). Sosyal medyanın nefret söylemi için kullanılması ifade özgürlüğ̈̈ değildir! $01 \quad 12, \quad 2021 \quad$ tarihinde https://yenimedya.wordpress.com/2012/01/20/sosyal-medyanin-nefret-soylemiicin-kullanilmasi-ifade-ozgurlugu-degildir/ adresinden alındı

Bulunmaz, B. (2015). Yeni medyada nefret söylemi ve üniversite öğrencilerine yönelik bir araştırma. Uşak Üniversitesi Sosyal Bilimler Dergisi, 8(1), 73-88.

Burgess, J. E. and Green, J.B. (2009). The entrepreneurial vlogger: Participatory culture beyond the professional-amateur divide. In Snickars, P, \& P. Vonderau (Eds.), The YouTube Reader (p. 89-107). Stockholm: National Library of Sweden/Wallflower Press.

Cafersoy, N. (2001). Elçibey Dönemi Azerbaycan dış politikası (Haziran 1992- Haziran 1993). Ankara: ASAM Yayınları.

Cohen-Almagor, R. (2011). Fighting hate and bigotry on the Internet. Policy \& Internet, $3(3), 1-26$.

Cornell, S. (1997). The unruly caucasus. Current History, 96(6), 341-347.

Cox, C. and Eibner, J. (1999). Ethnic cleansing in progress: War in Nagorno Karabakh. Zürih : Institute for Religious Minorities in Islamic World.

Çakmak, V. ve Baş, Ü. (2017). Benlik sunum aracı olarak Instagram kullanımı: Öğrenciler üzerine nitel bir araştırma. Uluslararası Hakemli İletişim ve Edebiyat Araştırmaları Dergisi, 17, 96-118.

Dearolph, A. (2014). Vlogging the museum: YouTube as a tool for audience engagement. Yüksek Lisans Tezi. ABD: Washington Üniversitesi.

Demirbaş, T. (2017). Nefret söylemi ve nefret suçları. Dokuz Eylül Üniversitesi Hukuk Fakültesi Dergisi 19, (Özel Sayı), 2693-2701.

Dondurucu, Z. ve Uluçay, A. (2015). Yeni medya ortamlarında nefret söylemi: Eşcinsellere yönelik nefret söylemi içeren videoların Youtube üzerinden incelenmesi. International Journal of Social Sciences Research, 1(3), 875-902.

Downe-Wamboldt R. N, B. (1992). Content analysis: Method, applications, and issues. Health Care for Women International, 13(3), 313-321.

Ellison, N., Heino, R. and Gibbs, J. (2006). Managing impressions online: Selfpresentation processes in the online dating environment. Journal of ComputerMediated Communication, 11(2), 415-441.

Erjavec, K. and Kovačič, M. (2012). You don't understand, this is a new war! Analysis of hate speech in news Web sites' comments. Mass Communication, 15(6), 899-920.

Fischer, E., Smith, A. and Yongjian, C. (2012). How does brand-related user-generated content differ across YouTube, Facebook, and Twitter? Journal of Interactive Marketing, 24(2), 137-147.

Goffman, E. (2009). Gündelik yaşamda benliğin sunumu. (B. Cezar, Çev.) İstanbul: Metis Yayınları.

Gofmann, E. (1963). Stigma: notes on the management of spoiled identity. Londra: Penguin Books. 
Gofmann, E. (1964). Behavior in public places: notes on the social organization of gatherings. New York: Free Press.

Gofmann, E. (1967). Interaction ritual. New York: Panteon Books.

Gofmann, E. (1971). Strategic interaction. Philadelphia: University of Pennsylvania Press.

Gofmann, E. (1986). Frame analysis: An essay on the organization of experience. Boston: Northeastern University Press.

Göregenli, M. (2013). Medya ve nefret söylemi kavramlar mecralar tartışmalar. M. Çınar (Ed.) içinde, Nefret söylemi ve nefret suçları (s. 57-73). İstanbul: Hrant Dink Vakfı Yayınları.

İnceoğlu, Y. ve Sözeri, C. (2012). Nefret suçlarında medyanın sorumluluğu: 'Ya sev ya terk et ya da.... Y. İnceoğlu (Ed.) içinde, Nefret söylemi ve/veya nefret suçları (s. 23-37). İstanbul: Ayrıntı Yayınları.

İşman, A., Buluş, B. ve Yüzüncüyıl, K. (2016). Sosyalleşmenin dijitale dönüşümü ve dijital benliğin sunumu. TRT Akademi, 1(2), 608-619.

Jones, E. E. and Pittman, T. S. (1982). Toward a general theory of strategic selfpresentation. In 1. Suls (Ed.), Psychological perspectives on the self, 1 (p. 231262). Hillsdale, NJ: Erlbaum.

Karaman, H. ve Işıklı, Ş. (2016). Twitter'daki dini ve etnik temelli nefret söylemlerinin analizi. AJIT-e: Biilişim Teknolojileri Online Dergisi, 7(25), 137-152.

Kaufmann, S. (2001). Modern hatreds: The sybolic politics of ethnic war. New York: Cornell University Press.

Khan, M. (2017). Social media engagement: What motivates user participation and consumption on YouTube? Computers in Human Behavior, 66, 236-247.

Kivisto, P. and Pitmann, D. (2012). Illuminating social life: classical and contemporary theory revisited. In P. Kivisto (Ed.), Illuminating social life: classical and contemporary theory revisited (p. 271-290). CA: Sage.

Koç, M. (2017). Dramaturjik teori çerçevesinde sosyal medyada engelli bireylerin benlik sunumu. Selçuk İletişim, 10(1), 262-281.

Kronegger, M. (1991). Transforming the Hermeneutic context from Nietzsche to Nancy. Bulletin de La Société Américaine de Philosophie de Langue Française, 3(1), 4557.

Kurt, G. (2019). Yeni medyada nefret söylemi: YouTube'da Suriyeli mültecilere karş1 üretilen nefret söylemi üzerine bir araştırma. The Journal of International Lingual Social, 5(1), 1-20.

Libaridian, G. (1988). The Karabakh File: Documents and facts on the question of Mountainous Karabakh. Cambridge: The Zorian Institute.

Ma, X. (2011). How may I impress you? A content analysis of online impression management tactics of YouTube beauty vloggers. Yüksek Lisans Tezi. Las Vegas: Nevada University.

Maigret, E. (2011). Medya ve iletişim sosyolojisi. (Ş. Tekeli, Çev.) İstanbul: İletişim Yayınları. 
Mouridian, C. (1990). The Mountainous Karabakh Question: Inter- ethnic conflict or decolonization crisis. Armenian Review, 43(2-3), 1-34.

Müftüoğlu, M. (2020). Kur'ân-1 Kerîm'e göre bela ve musibetler karşısında insanın durumu ve manevi değerler. Rumeli Íslami Araştırmalar Dergisi, 3(5), 8-27.

Oksman, V. and Turtiainen, J. (2004). Mobile communication as a social stage: Meaning of mobile communication in everyday life among teenagers in Finland. New Media \& Society, 6(3), 319-339.

Özdemir, Y. D. (2015). Taciz anlatılarında cinsiyetçi söylemlerin yeniden. Moment Dergi, 2(2), 80-103.

Özsoy, S. ve Yıldız, K. (2013). Türkiye'deki spor basınında nefret söylemi. International Journal of Social Science Research, 2(2), 46-60.

Öztekin, H. (2015). Yeni medyada nefret söylemi: Ekşi Sözlük örneği. Journal of International Social Research, 8(38), 925-937.

Sancar, M. (2007). Geçmişle hesaplaşma unutma kültüründen hatırlama kültürüne. İstanbul: İletişim Yayınları.

Sapmaz, A. (2008). Rusya'nın Transkafkasya politikası ve Türkiye’ye etkileri. İstanbul: Ötüken Neşriyat.

Savage, K. (2015). Understanding and engaging Youtube communities. Yüksek Lisans Tezi. ABD: Georgetown University.

Smith, J. (2012). Sharing intimate moments on Youtube: Women who vlog and their sense of community, friendship and privacy. Yüksek Lisans Tezi. ABD: Gonzaga University.

Smolla, R. (1990). Academic freedom, hate speech and the idea of a university. Law and Contemporary Problems, 53(3), 195-226.

Söylev, Ö. (2018). Sağlık hizmetlerinde manevi destek yöntemi olarak Duanın kullanılması. 4. Uluslararası Din Bilimleri Sempozyumu Bildiri Kitabı (s. 139145). Elazığ: Asos Yayınevi.

Strangelove, M. (2010). Watching YouTube: Extraordinary videos by ordinary people. Londra: University of Toronto Press.

Şahin, B. (2011). Metodoloji, bilimsel araştırma yöntemleri. Ankara: Anı Yayıncılık.

Şener, E. (2013). Örgütsel intikam üzerine nitel bir araştırma. Yüksek Lisans Tezi. Isparta: Süleyman Demirel Üniversitesi.

Taş, E. (2017). Yeni medyada nefret söylemi. Yeni Medya Elektronik Dergisi, 1(1), 60-71.

Taşdemir, H. (2002). Kafkasya'daki güvenlik sorunları. R. Yinanç ve H. Taşdemir (Ed.) içinde, Uluslararası Güvenlik Sorunları ve Türkiye (s. 215-230). Ankara: Seçkin Yayınları.

Uçar, F. (2015). Facebook'ta benlik sunumu ve toplumsal cinsiyet rolleri. Selçuk Üniversitesi Illetişim Fakültesi Dergisi, 9(1), 312-338.

Vardal, Z. B. (2015). Nefret söylemi ve yeni medya. Maltepe Üniversitesi Iletişim Fakültesi Dergisi, 2(1), 132-156. 
Wang, C. (2015). Do people purchase what they viewed from YouTube? The influence of attitude and perceived credibility of user-generated content on purchase intention. Master Thesis. ABD: Florida State University School of Communication.

Weber, A. (2009). Nefret söylemi el kitabı. Strasbourg: Avrupa Konseyi Yayınları.

Weber, R. P. (1990). Basic content analysis. CA: Sage.

Yerasimos, S. (2002). Milliyetler ve Sinırlar, Balkanlar, Kafkasya ve Orta Doğu. (Ş. Tekeli, Çev.) İstanbul: İletişim Yayınları.

Yıldız, H. (2017). Sosyal medya çağında nispetizm fenomeni. Harvard Business Review Türkiye, 6, 94-98.

Yüksel, A. (2007). Nitel araştırma- neden, nasıl, niçin? Ankara: Detay Yayıncılık.

Zhao, S., Grasmuck, S. and Martin, J. (2008). Identity construction on Facebook: Digital empowerment in anchored relationships. Computers in Human Behavior, 24(5), 1816-1836.

Destekleyen Kurum/Kuruluşlar: Herhangi bir kurum/kuruluştan destek alınmamıştır.

Çıkar Çatışması: Herhangi bir çıkar çatışması bulunmamaktadır. 